\title{
Changes in Plasma Level of LDH, CKMB and Lipid Profile in Rabbits Administered with Corn Silk Extract
}

\author{
Donatus F. N. Ozuruoke ${ }^{1}$, Mathew Folaranmi Olaniyan ${ }^{2^{*}}$, Faseesin Temitope ${ }^{2}$ \\ ${ }^{1}$ Department of Medical Laboratory Science Council of Nigera, Abuja. \\ ${ }^{2}$ Department of Medical Laboratory Science, Achievers University, Owo - Nigeria. \\ *Corresponding Author \\ Mathew Folaranmi OLANIYAN \\ Department of Medical Laboratory Science \\ Achievers University \\ Owo, Nigeria \\ Tel: +2348052248019 or +2347033670802 \\ Email: olaniyanmat@yahoo.com
}

Received: 23 September 2016; | Revised: 07 November 2016; | Accepted: 12 November 2016

\section{Abstract}

Background: Corn silk contains health promoting phytochemicals which could be applied in the treatment of cardiovascular diseases. Aim and objectives: This was designed to evaluate the effect of corn silk extract on lipid profile, CK-MB and LDH. Methods: Fifteen rabbits divided into three experimental groups of 5 rabbits each were studied. The control group(A) was not ingested with the extract throughout the period of study. Group B was ingested with the water extract for 3 weeks while group C was ingested with the mathanolic extract for 3 weeks. Plasma lipid profile, CK-MB and LDH were estimated in the rabbits biochemically by spectrophotometry. The rabbits were well kept and placed on normal diet throughout the period of study. Results: There was a significantly higher mean value of plasma Total Cholesterol Triglyceride in the control rabbits than those obtained in the test rabbits after one week of the administration of methanolic and aqueous extract of corn silk $(\mathrm{p}<0.05)$. There was a significantly lower mean value of plasma Total Cholesterol and Triglyceride in the control rabbits than those obtained in the test rabbits after two and three weeks of the administration of methanolic and aqueous extract of corn silk $(\mathrm{p}<0.05)$. There was a significantly lower mean value of plasma LDL- Cholesterol in the control rabbits than those obtained in the test rabbits after 2 and 3 weeks of the administration of methanolic and aqueous extract of corn silk $(\mathrm{p}<0.05)$. There was a significantly lower mean plasma CK-MB value in the test rabbits than the control rabbits after 3 weeks of administration of aqueous extract of corn silk $(\mathrm{p}<0.05)$. There was a significant decrease in Cholesterol and Triglyceride in the rabbits after one week of methanolic extract but prolong administration of the extract significantly increased the Cholesterol, Triglycerides and LDL-Cholesterol. The corn silk extract also has a lowering effect on CK-MB in rabbits administered with corn silk extract. Conclusion: Estimation of plasma CK-MB, Cholesterol, Triglyceride and LDL-Cholesterol in patient undergoing treatment with corn silk extract will be a useful indicies for effective management. 


\section{Introduction}

Zea mays L. (Family Poacea), is a cereal that produces one of the most important edible grains in the world. Maize originated from South America and was introduced to Nigeria in the 16th century. It is a tall annual plant with strong erect stalks and a fibrous root system having long narrow leaves spaced alternately on opposite sides of the stem. It produces ears that are enclosed by numerous husks, which are modified leaves. The grains are prepared and consumed in different parts of Nigeria and all over the world. In addition, the grains, leaves, cornsilks, stalk, and inflorescence of the maize plant are used for the treatment of several ailments. The corn silk is used as an antidiabetic and diuretic. The decoction of the silk is consumed for the treatment of urinary troubles and gallstones. The ash of the cob is used for the treatment of cough. The corn husk has been reported to contain arabinoxylan, which has immunological effects. Information obtained from some traditional medicine practitioners and some of their patients reveals that the decoction of the husk is also used for the treatment of pain and arthritis. Corn is one of the most widely grown cereal crops in the world and has become the third most important cereal crops other than wheat and rice [1]. Corn and its other plant parts are used in various food, agricultural and health applications [2].Corn silk refers to the stigmas from the female flowers of maize. Fresh corn silk resembles soft silk threads $10-20 \mathrm{~cm}$ long that are either light green or yellow- brown in color.

Corn silk has long been reported in ancient literatures to be able to assist with prostate problems, bed-wetting, carpel tunnel syndrome, edema and obesity [2]. It has also been used to lessen the effects of premenstrual syndrome, and said to promote relaxation. Corn silk was also reported to be useful in the treatment of urinary infections and cystitis. It is helpful in the management of frequent urination caused by irritation of the bladder and urethral walls as well as, for difficulty in passing urine, e.g. prostate disorders. It relaxes the lining of the urinary tubules and bladder, thus relieving irritation and improving urine excretion. Other biological activities of corn silk constituents well cited in literatures. These include: antibiotic activity toward corn earworm by a flavones glycoside maysin [3], isolated flavonoids from corn silk were found to act as anti- fatigue and antidiabetic agents [4].Traditionally corn silk has been used also as antilithiasic, uricosuric, and antiseptic. It is used for the treatment of gout, kidney stones, nephritis, and prostatitis, phenolics and flavonoids found in corn silk were thought to give it its antioxidant properties [5]. Corn silk also improves nutrient contents and physical characteristics of beef patties [6].

Flavonoids from corn silk have been investigated and confirmed to possess various pharmacological activities such as antihypertensive, anti-infectious, anti-oxidants and anti-diabetic. Therefore, corn silk can be used in the manufacture of health foods and treatment of different diseases such as diabetes.

Corn silk is reported to contain $2.5 \%$ of fats, $0.12 \%$ volatile oil, $3.8 \%$ gums, $2.7 \%$ resin, $1.15 \%$ of bitter glucosidic substances, $3.18 \%$ saponins, $0.05 \%$ alkaloids, cryptoxanthin, vitamins $\mathrm{c}$ and $\mathrm{k}$,sistosterol, stigmasterol, plant acids (malicc, tartaric etc), anthocyanins, minerals (potassium, calcium, magnesium, iron, aluminium etc. carbohydrate, steroids, protein $13 \%$ [7].

\section{Justification of the study}

Corn silk has been used in many part of the world for the treatment of many disease conditions. Inspite of its wide spread use, less study on the effect of cornsilk on cardiovascular markers has been done. Therefore the purpose of this study is to investigate the effect of cornsilk on $\mathrm{LDH}, \mathrm{CKMB}$, and lipid profile. 


\section{Aim and objectives of the study}

Aim

This study was designed to assess the possible effects of corn silk extracts on $\mathrm{LDH}$, CKMB and lipid profile levels in rabbits.

\section{Objectives}

To assess and measure the progressive change in the lipid profile levels of the rabbits after extract administration.

To determine the effect of the extract on cardiovascular marker (CKMB).

To determine the level of activity of LDH in the rabbits after administration of the extract.

\section{Hypothesis}

That there is no significant difference in the plasma level of CKMB, LDH and lipid profile in the rabbit before and after the administration of the corn silk extract.

That there is no significant difference in the plasma levels of CKMB,LDH and lipid profile in the control and the test subjects.

\section{Materials and methods}

\section{Experimental animals}

A total number of 15 rabbits were used for this study. The study was carried out at Achievers University, Owo, Ondo state, Nigeria. Rabbits weighing between 700g-1500g were procured were procured from Ado Ekiti, Ekiti State. The rabbits were weighed and allowed to acclimatize for two weeks under standard conditions in big wooden cages. They were fed with growers match feed (purchased from Opeyemi feed, Aderounmu street Okedogbon in Owo Ondo state Nigeria) and water throught the conduct of this research. They were maintained under standard conditions of humidity, temperature and environment.

\section{Study population and methodology Study population}

15 male and female albino rabbits (each weighing about 700-1400g) were supplied by animal house from Ado Ekiti. The rabbits were housed in cages and were were fed with feeds (growers match) throughout the period of this research.

\section{Grouping of experimental animals}

The rabbits were divided into three experimental groups of 5 rabbits each.

Group A: 5 rabbits in which neither corn water extract nor methanol extract was administered . this group serves as the control group.

Group B: 5 rabbits in which aqueous cornsilk extract was administered everyday per $\mathrm{Kg}$ body weight. $(400 \mathrm{mg} / \mathrm{kg})$ throughout the period of this research.

Group C: 5 rabbits in which methanol extract of cornsilk extract was administered everyday per $\mathrm{kg}$ body weight. $(400 \mathrm{mg} / \mathrm{kg})$ throughout the period of this research.

Blood samples were collected from the rabbits for estimation at one week intervals for the estimation of and lipid profile creatinine kinase MB and lactate dehydrogenase .

The rabbits were acclimated for two weeks and baseline samples were drawn from the rabbits before the administration of the extracts and were subjected to appropriate laboratory estimations. The extract was administered orally at a dose of $400 \mathrm{mg} / \mathrm{kg}$ bw/day for four weeks. The control group was left untreated. Body weight was recorded weekly.

\section{Measurement of the weight of rabbits}

The weight of the rabbits were measured using a weighing balance $785 \mathrm{~g}$

Category 1: 5 rats with average weight of $1040 \mathrm{~g}$

Category 2: 5 rats with average weight of

Category 3: 5 rats with average weight of $984 \mathrm{~g}$

\section{Distribution of rabbits into treatment groups}

In order to have fair representation of weight categories in all the treatment groups, rabbits in each weight categories were distributed into three groupsd each, such that, the number of rabbits in each group is equal with different weight. 


\section{Relabeling of rabbits according to treatment groups}

The rabbits were relabeled according to the treatment group tag in which they belong for example belly red group 2, fore head group 3 etc .

Collection of blood samples: Blood samples were collected after two weeks of acclimatization. Rabbits were fasted overnight and blood was withdrawn through vein puncture from the ear for baseline sampling. Blood samples was collected into lithium heparin for lipid profile estimation and EDTA bottles for LDH and CK-MB estimation. The blood was mixed, centrifuged, the supernatant (plasma) was pipetted out gently into plain bottles and was estimated instantly .

Determinations of total cholesterol (TC), triglycerides and high density lipoprotein cholesterol (HDL-C) were carried out using kits (Agapee) and low- density lipoprotein cholesterol (LDL-C) and other non HDL -C determination was calculated using method by Friedewald et al. [8].

\section{Method of Extraction of the corn silk}

Corn silk (dried cut stigmata of Zea mays L, Poaceae flowers) used for this investigation were collected and were identified and confirmed in January 2010 and authenticated and the voucher specimen was dried at room temperature and an ethanol-water (1:1) extraction was performed using maceration method by soaking in the solvent mixture. The extract was collected after removing the solvent and evaporated using the steam bath

Corn silk aqueous extract:

- Apparatus: steam bath ,clean bucket, electronic weighing balance

Procedure:

- $218.71 \mathrm{~g}$ of the air dried corn silk was weighed,and poured into a clean bucket

- About 5liters of distilled water with temperature at $40^{\circ} \mathrm{C}$ was poured into the bucket containing the cornsilk

- It was allowed to stay for 72 hours at room temperature

- It was then sieved and distributed into beakers
- The water content was evaporated using a steam bath

- The extract gotten was then weighed

Corm silk methanolic extract

Method: Soxhlet extraction method.

Principle: A solid material containing some of the desired compound is placed inside a thimble made from thick filter paper, which is loaded into the main chamber the soxhlet extractor is now placed onto this flask. The solvent is heated to reflux. The solvent vapor travels up a distillation arm and floods into the chamber housing the thimble of solid. The condenser ensures that any solvent vapor cools, and drips down into the chamber housing the solid material. The chamber containing the solid material is slowly filled with warm solvent.Some of the desired compound will then dissolve in the warm solvent. When the soxhlet chamber is almost full, the chamber is automatically emptied by a siphon side arm with the solvent running back down to the distillation flask. The thimble ensures that the solvent does not transport any solid material to the spill pot. This cycle may be allowed to repeat many times over hours or days. During each cycle, a portion of the non-volatile compound dissolves in the solvent after many cycles the desired compound is concentrated in the distillation flask.

After the extraction the solvent was removed, typically by means of a rotary evaporator, yielding the extracted compound [9].

\section{Analytical methods}

\section{Lipid profile \\ Total cholesterol}

Method: Enzymatic method.

Total cholesterol was determined by colorimetric enzymatic method using agape reagent. The manufacturer's instructions were strictly followed. Principle: The total cholesterol is determined after enzymatic hydrolysis and oxidation. The indicator quinoneimine is formed from hydrogen peroxide and 4- aminoantipyrine in the presence of phenol and peroxidase [10].

Cholesterol esterase

\footnotetext{
Cholesterol ester $+\mathrm{H}_{2} \mathrm{O}$
} 
cholesterol + fatty acids

Cholesterol esterase

Cholesterol $+\mathrm{O}_{2}$

4-cholesten 3-one $+\mathrm{H}_{2} \mathrm{O}_{2}$

$2 \mathrm{H}_{2} \mathrm{O}_{2}+$ phenol+4aminoantipyrine $\stackrel{\text { Peroxidase }}{\longrightarrow}$

red quinine $+4 \mathrm{H}_{2} \mathrm{O}$

The colored solution is read calorimetrically at $505 \mathrm{~nm}$ wavelength.

\section{Triglycerides}

Method: Enzymatic method for the determination of triglycerides using agape reagent. The manufacturer's instructions were strictly adhered to.

Principle: The triglycerides are determined after enzymatic hydrolysis with lipases. The indicator quinonemine is formed from hydrogen peroxide, 4- aminoantipyrine and 4-chlorophenol under the catalytic influence of peroxidase.

\section{LPL}

Triglycerides $+\mathrm{H}_{2} \mathrm{O} \longrightarrow$ glycerol + fatty

acids

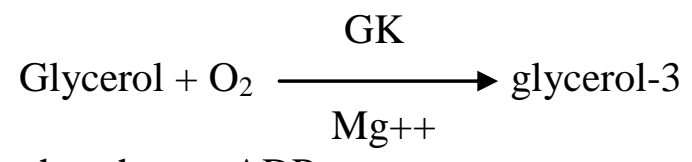

phosphate + ADP

Glycerol-3-phosphate+ $\mathrm{O}_{2} \stackrel{\mathrm{GPO}}{\longrightarrow}$

dihydroxyacetone phosphate $+\mathrm{H}_{2} \mathrm{O}_{2}$

$2 \mathrm{H}_{2} \mathrm{O}_{2}+4$ - aminoantipyrine + TOPS

violet colored complex

$\mathrm{GPO}=$ glycerol -3 -phospate

$\mathrm{LPL}=$ lipoprotein lipase

$\mathrm{GK}=$ glycerol kinase

\section{HDL Cholesterol}

Method: Precipitation method.

Principle: The chylomicrons, very low density lipoproteins and low density lipoproteins of serum are precipitated by phosphotungstic acid and magnesium ions. After centrifugation, high density lipoproteins are in the supernatant. HDL content of supernatant is measured by an enzymatic method.

LDL CHOLESTEROL

LDL-CHOL conc in $\mathrm{mg} / \mathrm{dl}=$ total cholesterol (HDL Chol+Triglycerides)

\section{Creatinine kinase $\mathrm{MB}$}

Method: IMMUNO-INHIBITION.

Methodology: It was estimated using Agapee reagent.the manufacturers instruction were strictly followed.

Principle: The procedure involves measurement of CK activity in the presence of an antibody CK$\mathrm{M}$ monomer. The antibody completely inhibits the activity of CK-MM and half of the activity of CK-MB, while not asffecting the $\mathrm{B}$ subunit activity of CK-MB and CK-BB. Then we use CK method to quantitatively determine CK-B activity. The CK-MB activity is obtained by multiplying the CK-B activity by two.

\section{Lactate dehydrogenase}

Method: ENZYMATIC METHOD.

Kinetic determination of $\mathrm{LDH}$ was performed using Agapee reagent and the manufacturers instruction was strictly followed.

Principle:

Pyruvate $+\mathrm{NADH}^{+}+\mathrm{H} \longrightarrow$ L-lactate $+\mathrm{NAD}^{+}$

\section{CALCULATION}

$\mathrm{LDH}-\mathrm{p}$ activity $(\mathrm{U} / \mathrm{L})=(\Delta \mathrm{OD} / \mathrm{min}) \times 16030$

\section{Results}

There was a significantly higher mean value of plasma Total Cholesterol Triglyceride in the control rabbits than the results obtained in the test rabbits after one week of the administration of methanolic and aqueous extract of corn silk $(\mathrm{p}<0.05)$. There was a significantly lower mean 
value of plasma Total Cholesterol Triglyceride in the control rabbits than the results obtained in the test rabbits after two and three weeks of the administration of methanolic and aqueous extract of corn silk $(\mathrm{p}<0.05)$. There was no significant difference mean value of plasma Total
Cholesterol Triglyceride in the control rabbits compared with the results obtained in the test rabbits before the administration of methanolic and aqueous extract of corn silk ( $p>0.05$ ) (Table1, Figure1)

Table 1. Changes in biochemical parameters in the Rabbits before and after treatment.

\begin{tabular}{|c|c|c|c|c|c|c|c|c|}
\hline & & & & & & & \begin{tabular}{|l|} 
Control \\
versus \\
group B
\end{tabular} & $\begin{array}{l}\text { Control } \\
\text { versus } \\
\text { group C }\end{array}$ \\
\hline \multirow[t]{2}{*}{$\begin{array}{l}0 \\
\text { (Before } \\
\text { administration) }\end{array}$} & $\begin{array}{l}\text { Total } \\
\text { Cholesterol }\end{array}$ & $\begin{array}{l}\text { Mean } \\
\pm \\
\text { SEM }\end{array}$ & $52.38 \pm 5.02$ & $55.944 \pm 5.33$ & $50.47 \pm 6.98$ & $\begin{array}{l}\text { 't' } \\
\text { Value } \\
\mathrm{P} \\
\text { Value }\end{array}$ & $\begin{array}{l}0.497 \\
0.32\end{array}$ & $\begin{array}{l}0.78 \\
0.23\end{array}$ \\
\hline & Triglyceride & $\begin{array}{l}\text { Mean } \\
\pm \\
\text { SEM }\end{array}$ & $\begin{array}{l}34.215 \quad \pm \\
5.34\end{array}$ & $36.07 \pm 3.13$ & $37.644 \pm 4.57$ & $\begin{array}{l}\text { 't' } \\
\text { Value } \\
\mathrm{P} \\
\text { Value }\end{array}$ & $\begin{array}{l}0.28 \\
0.39\end{array}$ & $\begin{array}{l}0.28 \\
0.39\end{array}$ \\
\hline \multirow[t]{2}{*}{$\begin{array}{l}1 \\
\left(1^{\text {st }} \text { week after }\right. \\
\text { administration })\end{array}$} & $\begin{array}{l}\text { Total } \\
\text { Cholesterol }\end{array}$ & $\begin{array}{l}\text { Mean } \\
\pm \\
\text { SEM }\end{array}$ & $\begin{array}{ll}42.855 \quad \pm \\
3.37\end{array}$ & $8.705 \pm 6.19$ & $45.714 \pm 2.42$ & $\begin{array}{l}\text { t' } \\
\text { Value } \\
\text { P } \\
\text { Value }\end{array}$ & $\begin{array}{l}0.71 \\
0.26\end{array}$ & $\begin{array}{l}1.18 \\
0.14\end{array}$ \\
\hline & Triglyceride & $\begin{array}{l}\text { Mean } \\
\pm \\
\text { SEM }\end{array}$ & $\begin{array}{ll}47.612 \quad \pm \\
3.1\end{array}$ & $6.072 \pm 0.99$ & $8.78 \pm 2.92$ & $\begin{array}{l}\text { 't' } \\
\text { Value } \\
\mathrm{P} \\
\text { Value }\end{array}$ & $\begin{array}{l}* 2.15 \\
* 0.037\end{array}$ & $\begin{array}{l}{ }^{\times 9.946} \\
3 \mathrm{E}-05\end{array}$ \\
\hline \multirow{2}{*}{$\begin{array}{l}2 \\
\left(2^{\text {nd }} \quad \text { week }\right. \\
\text { after } \\
\text { administration })\end{array}$} & $\begin{array}{l}\text { Total } \\
\text { Cholesterol }\end{array}$ & $\begin{array}{l}\text { Mean } \\
\pm \\
\text { SEM }\end{array}$ & $\begin{array}{ll}28.27 \quad \pm \\
1.51\end{array}$ & $61.7 \pm 7.27$ & $53.9 \pm 4.01$ & $\begin{array}{l}\text { t' } \\
\text { Value } \\
\mathrm{P} \\
\text { Value }\end{array}$ & $\begin{array}{l}* 4.84 \\
* 0.002\end{array}$ & $\begin{array}{l}* 4.398 \\
* 0.0058\end{array}$ \\
\hline & Triglyceride & $\begin{array}{l}\text { Mean } \\
\pm \\
\text { SEM }\end{array}$ & $\begin{array}{ll}13.9 & \pm \\
0.997 & \end{array}$ & $44.78 \pm 7.77$ & $44.73 \pm 2.81$ & $\begin{array}{l}\text { 't' } \\
\text { Value } \\
\mathrm{P} \\
\text { Value }\end{array}$ & $\begin{array}{l}* 3.911 \\
* 0.0086\end{array}$ & $\begin{array}{l}* 9.104 \\
* 0.00013\end{array}$ \\
\hline \multirow[t]{2}{*}{$\begin{array}{l}3 \\
\left(3^{\text {rd }} \text { week after }\right. \\
\text { administration })\end{array}$} & $\begin{array}{l}\text { Total } \\
\text { Cholesterol }\end{array}$ & $\begin{array}{l}\text { Mean } \\
\pm \\
\text { SEM }\end{array}$ & $45.85 \pm 3.9$ & $153.59 \pm 41.48$ & $116.61 \pm 15.19$ & $\begin{array}{l}\mathrm{t}^{\prime} \\
\text { Value } \\
\mathrm{P} \\
\text { Value }\end{array}$ & $\begin{array}{l}* 2.18 \\
* 0.04\end{array}$ & $\begin{array}{l}* 3.845 \\
* 0.006\end{array}$ \\
\hline & Triglyceride & $\begin{array}{l}\text { Mean } \\
\pm \\
\text { SEM }\end{array}$ & $\begin{array}{ll}20.67 \quad \pm \\
0.87\end{array}$ & $75.75 \pm 25.88$ & $67.46 \pm 8.52$ & $\begin{array}{l}\text { t' } \\
\text { Value } \\
\mathrm{P} \\
\text { Value } \\
\end{array}$ & $\begin{array}{l}* 2.151 \\
* 0.048\end{array}$ & $\begin{array}{l}* 4.63 \\
* 0.003\end{array}$ \\
\hline
\end{tabular}


Table 2. Comparative evaluation of changes in Lipid profile in the Rabbits before and after treatments.

\begin{tabular}{|c|c|c|c|c|c|c|c|c|}
\hline \multirow[b]{2}{*}{ Week } & \multirow[t]{2}{*}{ Parameter } & & \multirow{2}{*}{$\begin{array}{l}\text { Control } \\
\text { Group } \\
\text { A }\end{array}$} & \multirow{2}{*}{$\begin{array}{l}\text { GROUP B } \\
\text { ADMINISTERD } \\
\text { WITH } \\
\text { AQUEOUS } \\
\text { EXTRACT }\end{array}$} & \multirow{2}{*}{$\begin{array}{l}\text { GROUP C } \\
\text { ADMINISTERD } \\
\text { WITH } \\
\text { METHANOLIC } \\
\text { EXTRACT }\end{array}$} & & \multicolumn{2}{|c|}{ Test Groups } \\
\hline & & & & & & & $\begin{array}{l}\text { Control } \\
\text { versus } \\
\text { group B }\end{array}$ & $\begin{array}{l}\text { Control } \\
\text { versus } \\
\text { group C }\end{array}$ \\
\hline \multirow{3}{*}{$\begin{array}{l}0 \\
\text { (Before } \\
\text { administration) }\end{array}$} & $\begin{array}{l}\text { HDL- } \\
\text { CHOL }\end{array}$ & $\begin{array}{l}\text { Mean } \\
\pm \\
\text { SEM }\end{array}$ & $\begin{array}{l}27.93 \pm \\
5.34\end{array}$ & $27.82 \pm 3.92$ & $25.43 \pm 2.81$ & $\begin{array}{l}\text { 't' } \\
\text { Value }\end{array}$ & 0.0187 & 0.48 \\
\hline & & & & & & Value & 0.49 & 0.32 \\
\hline & $\begin{array}{l}\text { LDL- } \\
\text { CHOL }\end{array}$ & $\begin{array}{l}\text { Mean } \\
\pm \\
\text { SEM }\end{array}$ & $\begin{array}{l}37.35 \pm \\
2.39\end{array}$ & $43.16 \pm 5.17$ & $37.85 \pm 5.93$ & $\begin{array}{l}\text { ' } \mathrm{t} \text { ' } \\
\text { Value } \\
\mathrm{P} \\
\text { Value }\end{array}$ & $\begin{array}{l}1.46 \\
0.097\end{array}$ & $\begin{array}{l}0.066 \\
0.48\end{array}$ \\
\hline \multirow[t]{2}{*}{$\begin{array}{l}1 \\
\left(1^{\text {st }} \text { week after }\right. \\
\text { administration })\end{array}$} & $\begin{array}{l}\text { HDL- } \\
\text { CHOL }\end{array}$ & $\begin{array}{l}\text { Mean } \\
\pm \\
\text { SEM }\end{array}$ & $\begin{array}{l}25.96 \pm \\
2.47\end{array}$ & $27.68 \pm 2.92$ & $24.74 \pm 2.03$ & $\begin{array}{l}\text { 't' } \\
\text { Value } \\
\mathrm{P} \\
\text { Value }\end{array}$ & $\begin{array}{l}0.435 \\
0.338\end{array}$ & 0.23 \\
\hline & $\begin{array}{l}\text { LDL- } \\
\text { CHOL }\end{array}$ & $\begin{array}{l}\text { Mean } \\
\pm \\
\text { SEM }\end{array}$ & $\begin{array}{l}35.92 \pm \\
3.38\end{array}$ & $40.86 \pm 5.75$ & $39.21 \pm 17.08$ & $\begin{array}{l}\text { 't' } \\
\text { Value } \\
\mathrm{P} \\
\text { Value }\end{array}$ & $\begin{array}{l}0.707 \\
0.251\end{array}$ & $\begin{array}{l}0.205 \\
0.877\end{array}$ \\
\hline \multirow{2}{*}{$\begin{array}{l}2 \\
\left(2^{\text {nd }} \quad \text { week }\right. \\
\text { after } \\
\text { administration) }\end{array}$} & $\begin{array}{l}\text { HDL- } \\
\text { CHOL }\end{array}$ & $\begin{array}{l}\text { Mean } \\
\pm \\
\text { SEM }\end{array}$ & $\begin{array}{l}11.8 \pm \\
2.78\end{array}$ & $14.8 \pm 2.07$ & $13.68 \pm 1.33$ & $\begin{array}{l}\text { '' } \\
\text { Value } \\
\mathrm{P} \\
\text { Value }\end{array}$ & $\begin{array}{l}1.162 \\
0.149\end{array}$ & $\begin{array}{l}1.022192 \\
0.177\end{array}$ \\
\hline & $\begin{array}{l}\text { LDL- } \\
\text { CHOL }\end{array}$ & $\begin{array}{l}\text { Mean } \\
\pm \\
\text { SEM }\end{array}$ & $\begin{array}{l}14.21 \pm \\
3.95\end{array}$ & $49.74 \pm 5.83$ & $44.59 \pm 2.56$ & $\begin{array}{l}\text { ' } \mathrm{t} \text { ' } \\
\text { Value } \\
\mathrm{P} \\
\text { Value }\end{array}$ & $\begin{array}{l}* 5.73 \\
* 0.00061\end{array}$ & $\begin{array}{l}* 9.08 \\
* 5 \mathrm{E}-05\end{array}$ \\
\hline \multirow[t]{2}{*}{$\begin{array}{l}3 \\
\left(3^{\text {rd }} \text { week after }\right. \\
\text { administration })\end{array}$} & $\begin{array}{l}\text { HDL- } \\
\text { CHOL }\end{array}$ & $\begin{array}{l}\text { Mean } \\
\pm \\
\text { SEM }\end{array}$ & $\begin{array}{l}12.31 \pm \\
1.62\end{array}$ & $23.51 \pm 9.22$ & $18.29 \pm 1.31$ & $\begin{array}{l}\text { t' } \\
\text { Value } \\
\mathrm{P} \\
\text { Value }\end{array}$ & $\begin{array}{l}1.018 \\
0.177\end{array}$ & $\begin{array}{l}1.006 \\
0.186\end{array}$ \\
\hline & $\begin{array}{l}\text { LDL- } \\
\text { CHOL }\end{array}$ & $\begin{array}{l}\text { Mean } \\
\pm \\
\text { SEM } \\
\text { ، }\end{array}$ & $\begin{array}{l}16.67 \pm \\
2.12\end{array}$ & $133.74 \pm 34.79$ & $101,13 \pm 18.11$ & $\begin{array}{l}\text { t' } \\
\text { Value } \\
\mathrm{P} \\
\text { Value }\end{array}$ & $\begin{array}{l}* 5.478 \\
* 0.003\end{array}$ & $\begin{array}{l}* 3.98 \\
* 0.008\end{array}$ \\
\hline
\end{tabular}


Table 3. Comparative evaluation of changes in LDH and CK-MB in the Rabbits before and after treatments.

\begin{tabular}{|c|c|c|c|c|c|c|c|c|}
\hline \multirow[b]{2}{*}{ Week } & \multirow[t]{2}{*}{ Parameter } & & \multirow{2}{*}{$\begin{array}{l}\text { Control } \\
\text { Group } \\
\text { A }\end{array}$} & \multirow[b]{2}{*}{$\begin{array}{l}\text { GROUP } \\
\text { ADMINISTERD } \\
\text { WITH } \\
\text { AQUEOUS } \\
\text { EXTRACT }\end{array}$} & \multirow{2}{*}{$\begin{array}{l}\text { GROUP C } \\
\text { ADMINISTERD } \\
\text { WITH } \\
\text { METHANOLIC } \\
\text { EXTRACT }\end{array}$} & & \multicolumn{2}{|c|}{ Test Groups } \\
\hline & & & & & & & $\begin{array}{l}\text { Control } \\
\text { versus } \\
\text { group } \\
\text { B }\end{array}$ & $\begin{array}{l}\text { Control } \\
\text { versus } \\
\text { group } \\
\text { C }\end{array}$ \\
\hline \multirow[t]{2}{*}{$\begin{array}{l}0 \\
\text { (Before } \\
\text { administration) }\end{array}$} & CK-MB & $\begin{array}{l}\text { Mean } \\
\pm \\
\text { SEM }\end{array}$ & $29.75 \pm 0.86$ & $27.5 \pm 2.6$ & $25.5 \pm 3.28$ & $\begin{array}{l}\text { ' } \mathrm{t} \text { ' } \\
\text { Value } \\
\mathrm{P} \\
\text { Value }\end{array}$ & $\begin{array}{l}0.82 \\
0.221\end{array}$ & $\begin{array}{l}1.26 \\
0.128\end{array}$ \\
\hline & $\mathrm{LDH}$ & $\begin{array}{l}\text { Mean } \\
\pm \\
\text { SEM }\end{array}$ & $337.5 \pm 15.8$ & $347.5 \pm 23.2$ & $315 \pm 25.8$ & $\begin{array}{l}\text { ' } \mathrm{t} \text { ' } \\
\text { Value } \\
\mathrm{P} \\
\text { Value }\end{array}$ & $\begin{array}{l}0.34 \\
0.37\end{array}$ & $\begin{array}{l}0.76 \\
0.239\end{array}$ \\
\hline \multirow[t]{2}{*}{$\begin{array}{l}1 \\
\left(1^{\text {st }} \text { week after }\right. \\
\text { administration })\end{array}$} & CK-MB & $\begin{array}{l}\text { Mean } \\
\pm \\
\text { SEM } \\
\end{array}$ & $27.51 \pm 15.15$ & $11.35 \pm 3.05$ & $22.58 \pm 11.2$ & $\begin{array}{l}\mathrm{t} \\
\text { Value } \\
\mathrm{P} \\
\text { Value }\end{array}$ & $\begin{array}{l}1.18 \\
0.15\end{array}$ & $\begin{array}{l}0.27 \\
0.41\end{array}$ \\
\hline & $\mathrm{LDH}$ & $\begin{array}{l}\text { Mean } \\
\pm \\
\text { SEM }\end{array}$ & $579.4 \pm 191.94$ & $101.6 \pm 14.3$ & $260.5 \pm 52.05$ & $\begin{array}{l}\text { ' } \mathrm{t} \text { ' } \\
\text { Value } \\
\mathrm{P} \\
\text { Value }\end{array}$ & $\begin{array}{l}2.03 \\
0.06\end{array}$ & $\begin{array}{l}1.50 \\
0.10\end{array}$ \\
\hline \multirow{2}{*}{$\begin{array}{l}2 \\
\left(2^{\text {nd }} \quad \text { week }\right. \\
\text { after } \\
\text { administration })\end{array}$} & CK-MB & $\begin{array}{l}\text { Mean } \\
\pm \\
\text { SEM } \\
\text { ، }\end{array}$ & $47.53 \pm 9.74$ & $18.57 \pm 3.58$ & $47.04 \pm 17.08$ & $\begin{array}{l}\text { t' } \\
\text { Value } \\
\mathrm{P} \\
\text { Value }\end{array}$ & $\begin{array}{l}3.16 \\
0.01\end{array}$ & $\begin{array}{l}0.003 \\
0.499\end{array}$ \\
\hline & $\mathrm{LDH}$ & $\begin{array}{l}\text { Mean } \\
\pm \\
\text { SEM }\end{array}$ & $366 \pm 220.68$ & $378.7 \pm 87.4$ & $274.1 \pm 66.6$ & $\begin{array}{l}\text { ' } \mathrm{t} \text { ' } \\
\text { Value } \\
\mathrm{P} \\
\text { Value }\end{array}$ & $\begin{array}{l}0.23 \\
0.42\end{array}$ & $\begin{array}{l}0.75 \\
0.25\end{array}$ \\
\hline \multirow[t]{2}{*}{$\begin{array}{l}3 \\
\left(3^{\text {rd }} \text { week after }\right. \\
\text { administration })\end{array}$} & CK-MB & $\begin{array}{l}\text { Mean } \\
\pm \\
\text { SEM }\end{array}$ & $62.8 \pm 5.02$ & $17.54 \pm 8.82$ & $81.72 \pm 47.38$ & $\begin{array}{l}\text { t' } \\
\text { Value } \\
\mathrm{P} \\
\text { Value }\end{array}$ & $\begin{array}{l}* 7.14 \\
* 0.001\end{array}$ & $\begin{array}{l}0.68 \\
0.27\end{array}$ \\
\hline & $\mathrm{LDH}$ & $\begin{array}{l}\text { Mean } \\
\pm \\
\text { SEM }\end{array}$ & $395 \pm 6.3$ & $385 \pm 2.5$ & $310 \pm 234$ & $\begin{array}{l}\text { t' } \\
\text { Value } \\
\mathrm{P} \\
\text { Value }\end{array}$ & 1.57 & $\begin{array}{l}0.67 \\
0.27\end{array}$ \\
\hline
\end{tabular}


There was a significantly lower mean value of plasma LDL- Cholesterol in the control rabbits than the results obtained in the test rabbits after 2 and 3 weeks of the administration of methanolic and aqueous extract of corn silk $(\mathrm{p}<0.05)$. There was no significant difference mean value of plasma HDL-Cholesterol in the control rabbits compared with the results obtained in the test rabbits at the baseline and after 1,2,3 weeks of the administration of methanolic and aqueous extract of corn silk ( $p>0.05)$. There was no significant difference mean value of plasma LDLCholesterol in the control rabbits compared with the results obtained in the test rabbits at the baseline and after 1 week of the administration of methanolic and aqueous extract of corn silk (p>0.05) (Table2, Figure 2).
There was a significantly lower mean plasma CK-MB value in the test rabbits than the control rabbits after 3 weeks of administration of aqueous extract of corn silk $(\mathrm{p}<0.05)$. However there was no significant difference in the mean plasma value of LDH in the control rabbits compared with the test rabbits after 1,2,3 weeks of methanolic and aqueous extract of corn silk ( $>0.05$ ). The results obtained also revealed no significant difference in the plasma value of CK$\mathrm{MB}$ in the control rabbits compared with the test rabbits after 1,2,3 weeks of administration of methanolic extract of corn silk $(p>0.05)$. The results obtained also revealed no significant difference in the plasma value of CK-MB in the control rabbits compared with the test rabbits after 1,2 weeks of administration of aqueous extract of corn silk ( $\mathrm{p}>0.05)$ (Table3, figure 3).

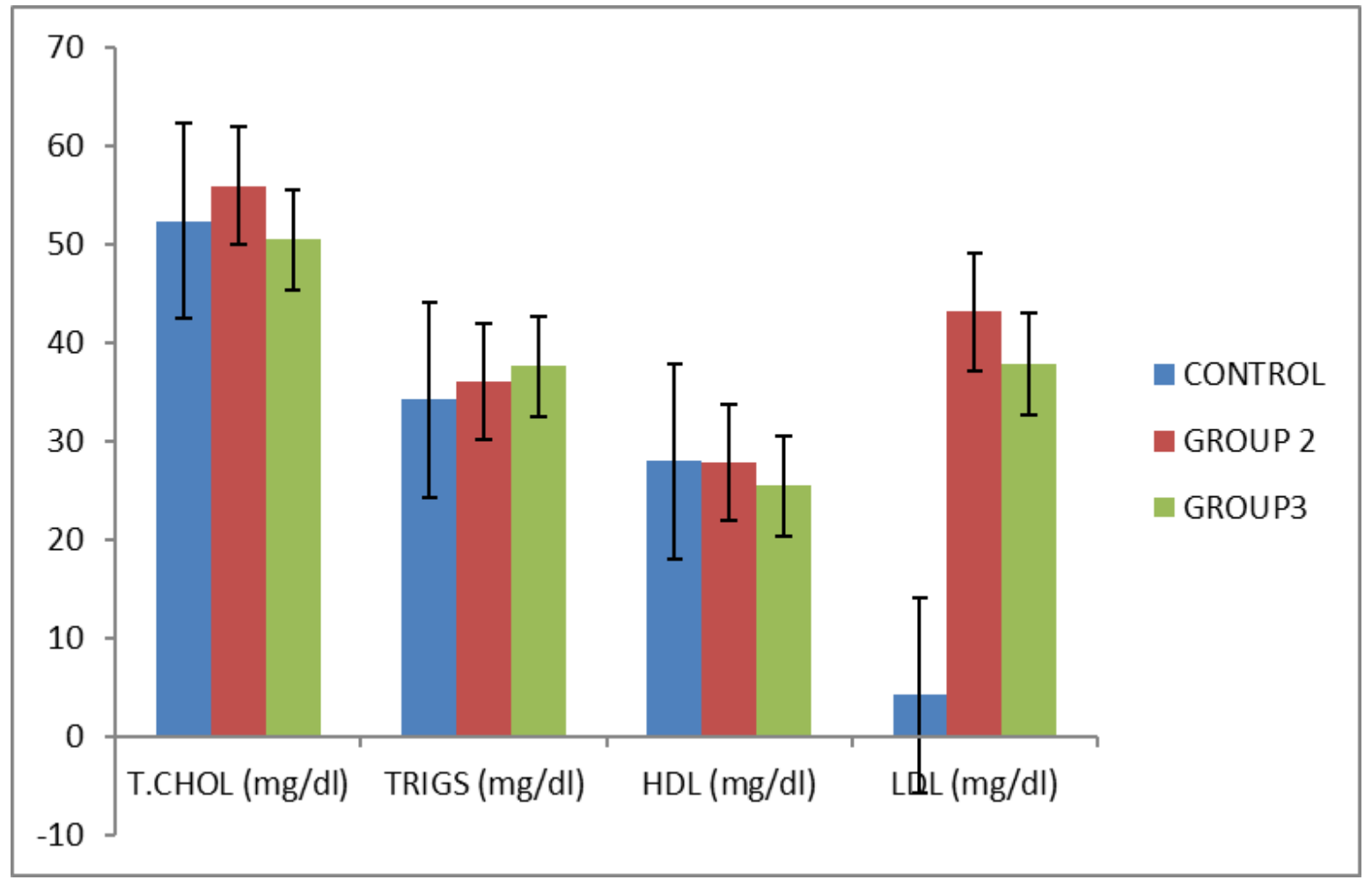

Figure 1. Baseline samples.

Group One: Aqueous Extract

Group Two: Methanolic Extract. 


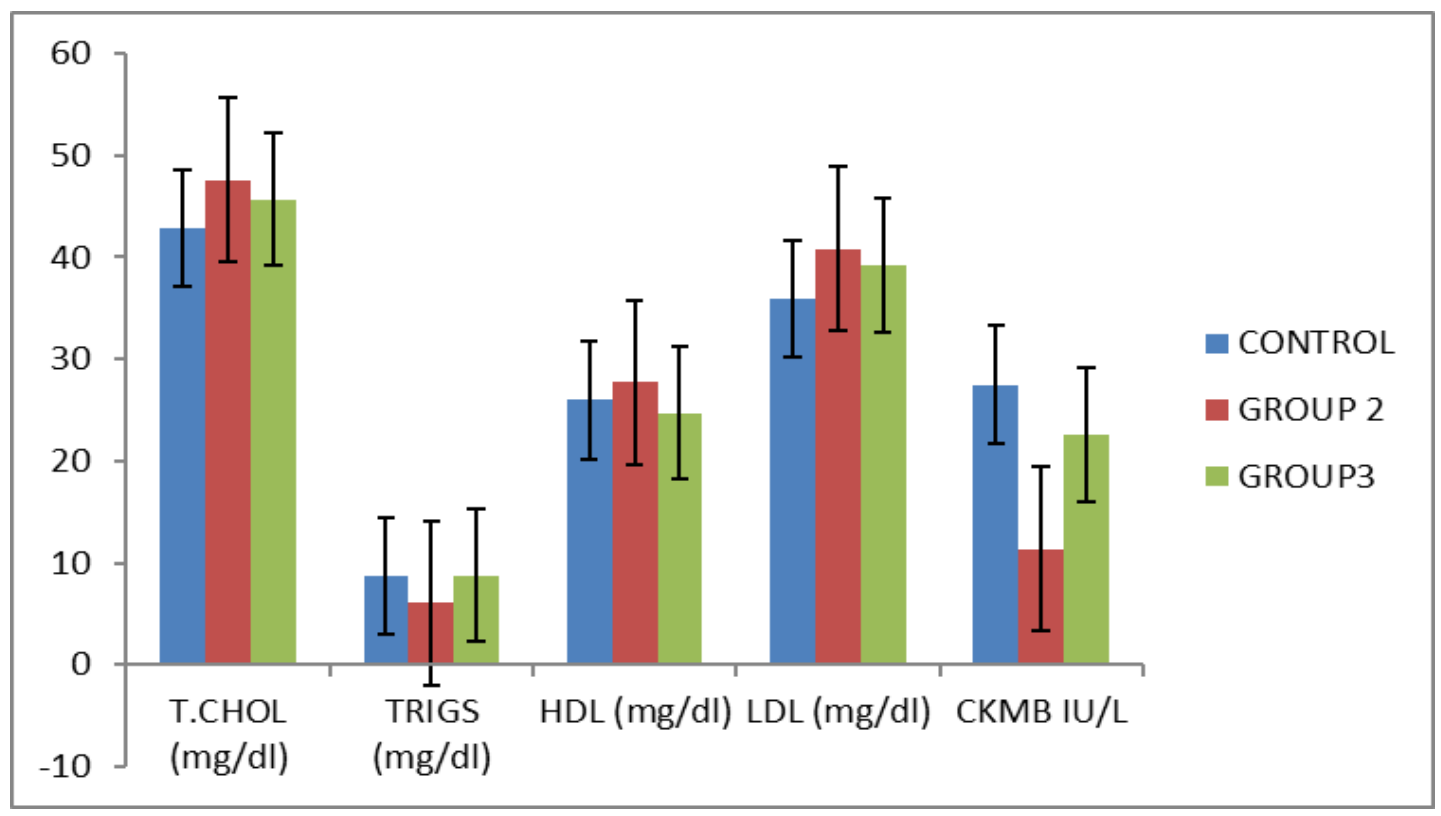

Figure 2. The Chart Below Shows the Effect of Cornsilk Extract on the Rabbits After One Week of Administration of Both Aqueous and Methanolic Extract

Group One: Aqueous Extract

Group Two: Methanolic Extract

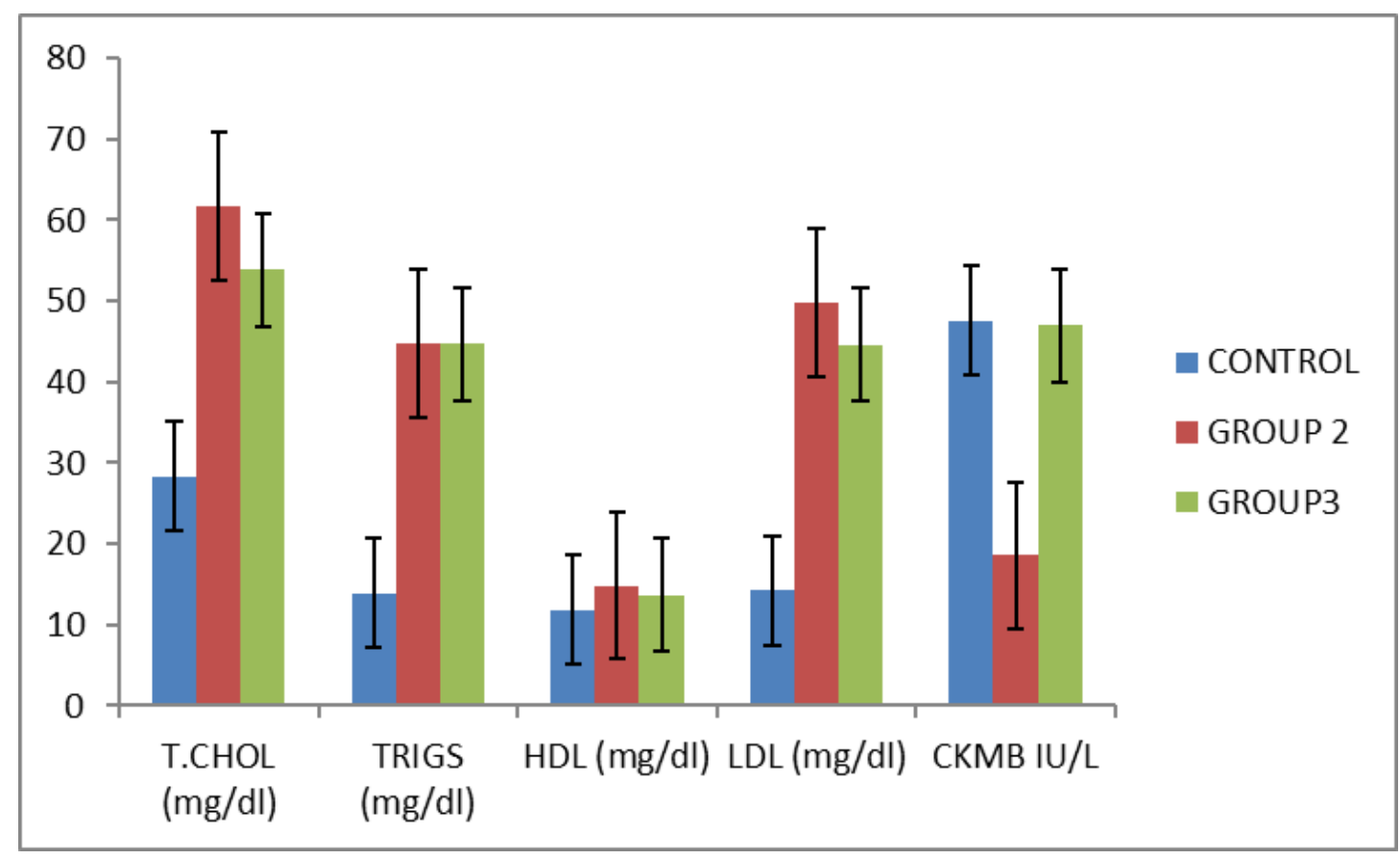

Figure 3. The Chart Below Shows the Effect of Corn silk Extract on the Rabbits After Three Weeks of Administration of Corn Silk Extracts.

Group One: Aqueous Extract

Group Two: Methanolic Extract 


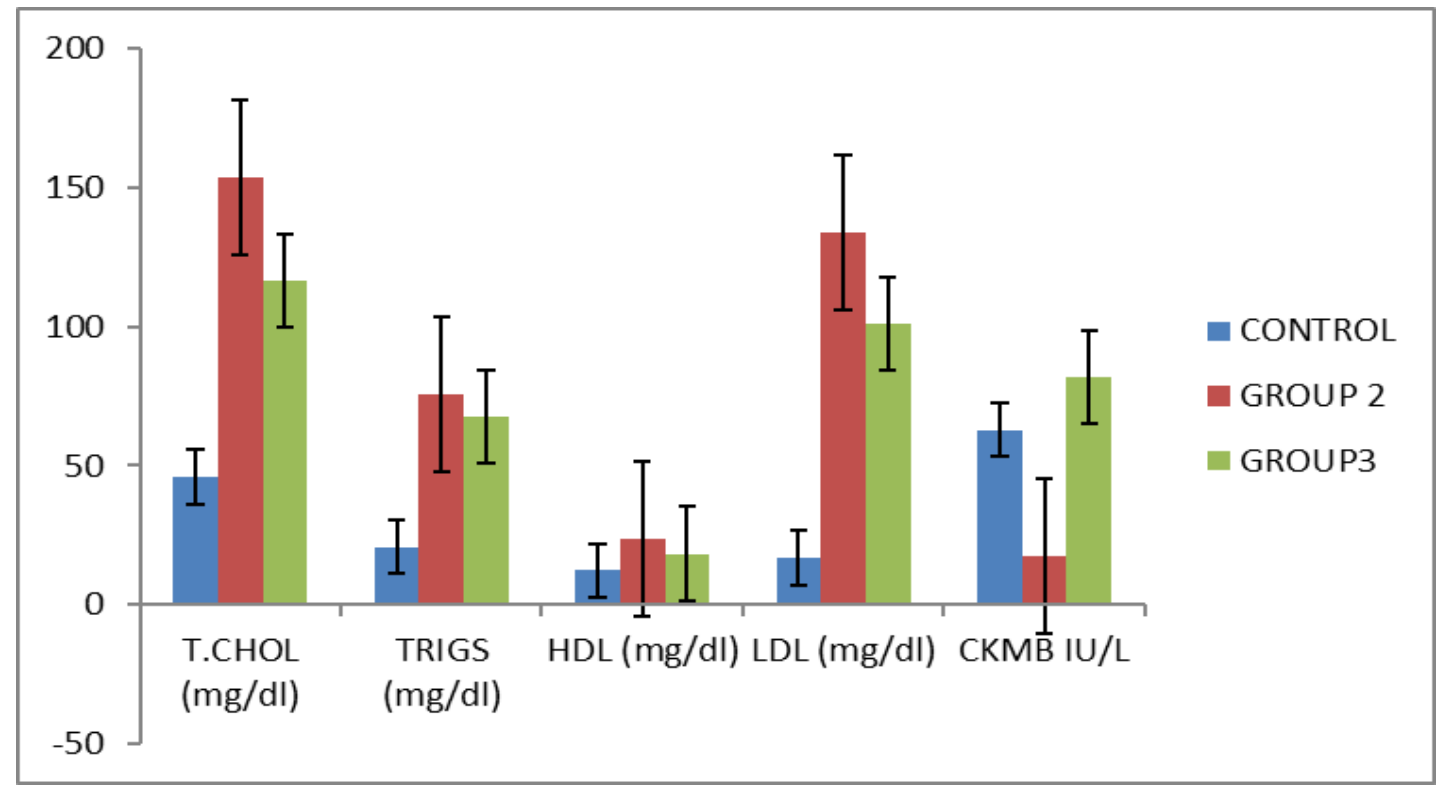

Figure 4. The Chart Below Shows the Effect of Corn silk Extract on the Rabbits After Three Weeks of Administration of Corn Silk Extracts.

Group One: Aqueous Extract

Group Two: Methanolic Extract

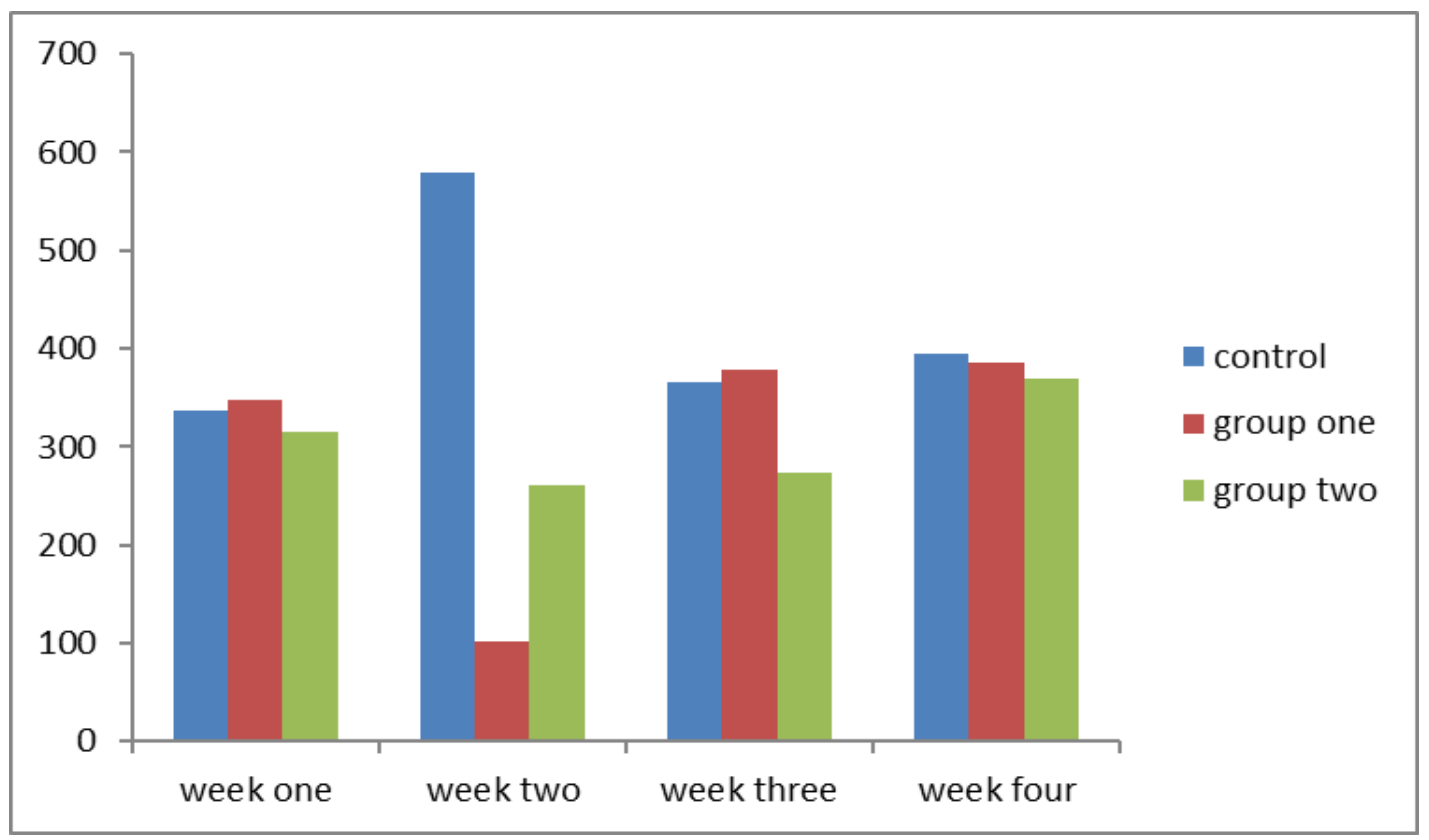

Figure 5. Below Shows the Effect of Corn Silk on LDH for the Second and Third Weeks of Administration of Corn Silk.

Group One: Aqueous Extract

Group Two: Methanolic Extract 


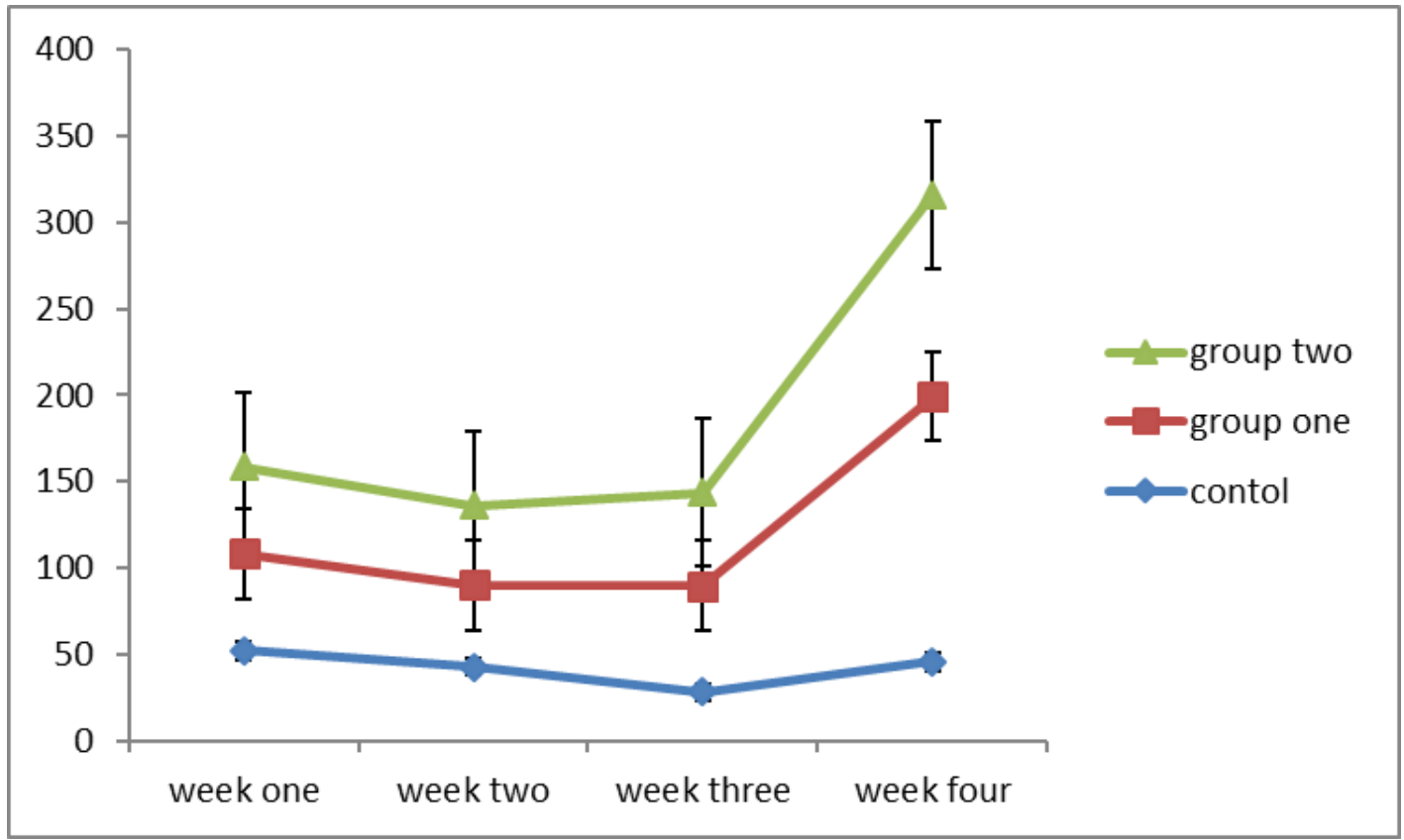

Figure 6. Shows the comparative illustration of the changes in the plasma Total Cholesterol (mg/dl) level from week 1 to week 4 in the rabbits administered with both aqueous extract and methanolic extract of corn silk.

Group One: Aqueous Extract

Group Two: Methanolic Extract

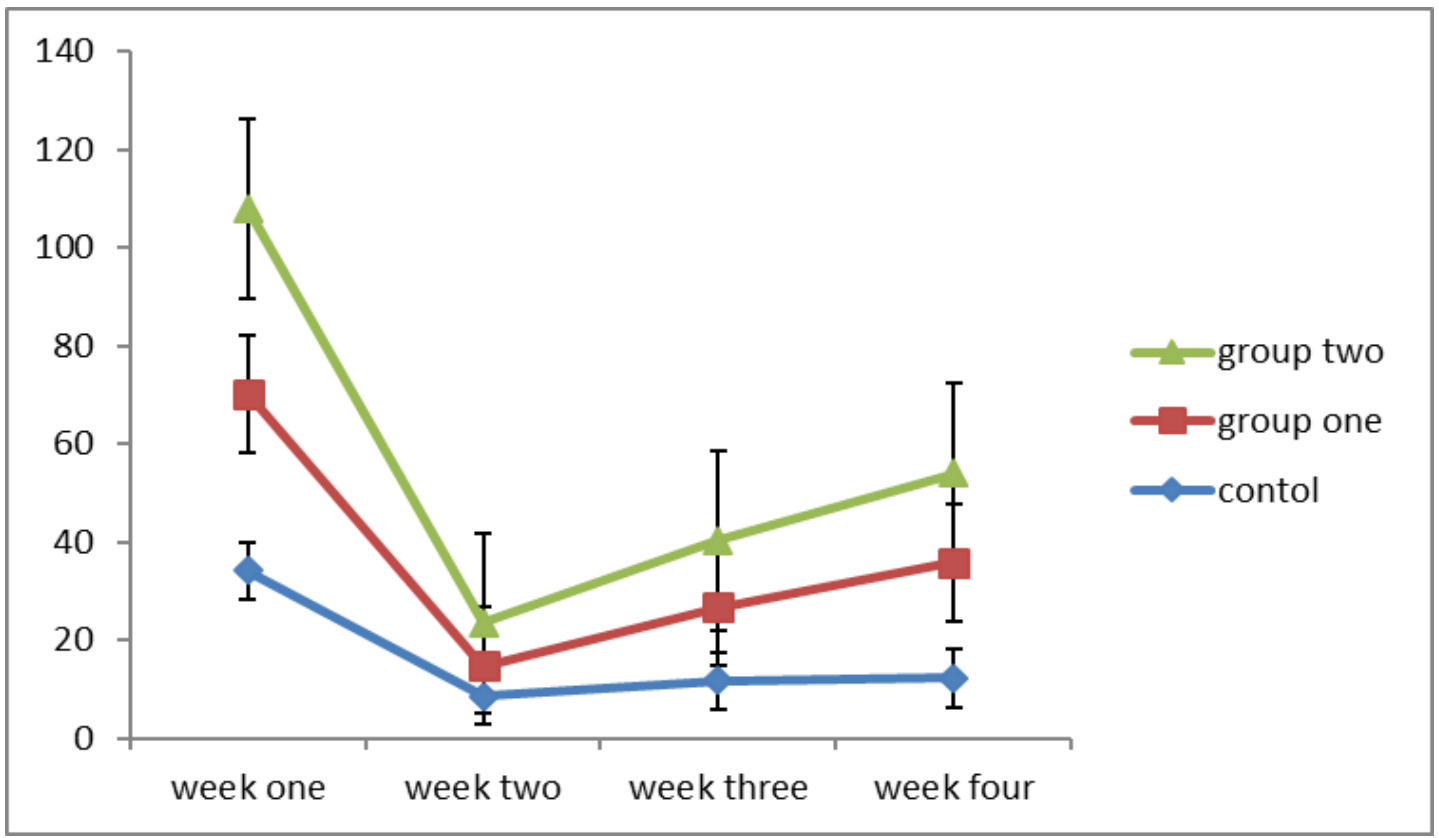

Figure 7. Shows the comparative illustration of the changes in the plasma triglyceride level from week 1 to week 4 in the rabbits administered with both aqueous extract and methanolic extract of corn silk.

Group One: Aqueous Extract

Group Two: Methanolic Extract 


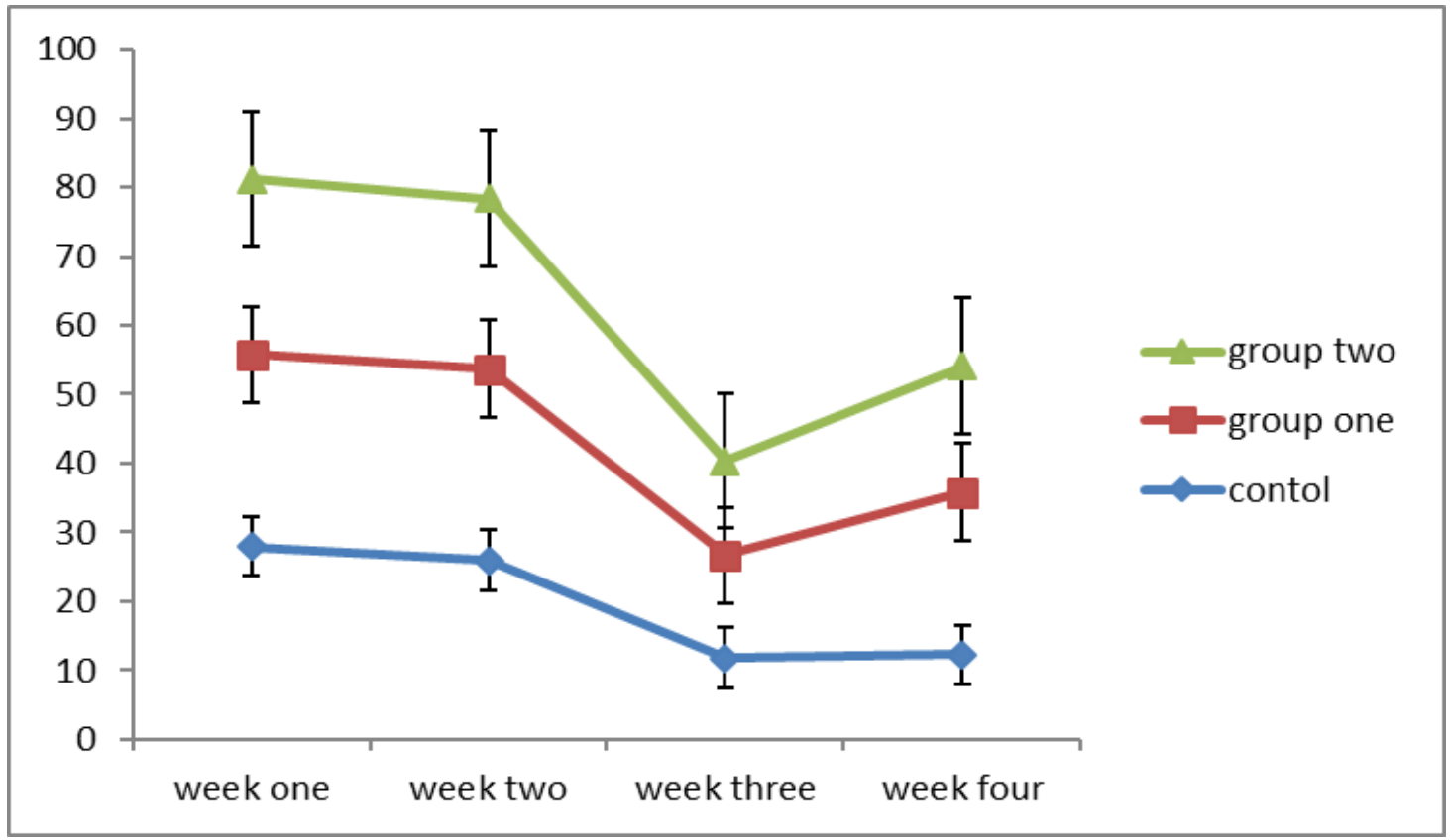

Figure 8. Shows the comparative illustration of the changes in the plasma HDL levels from week 1 to week 4 in the rabbits administered with both aqueous extract and methanolic extract of corn silk.

Group One: Aqueous Extract

Group Two: Methanolic Extract

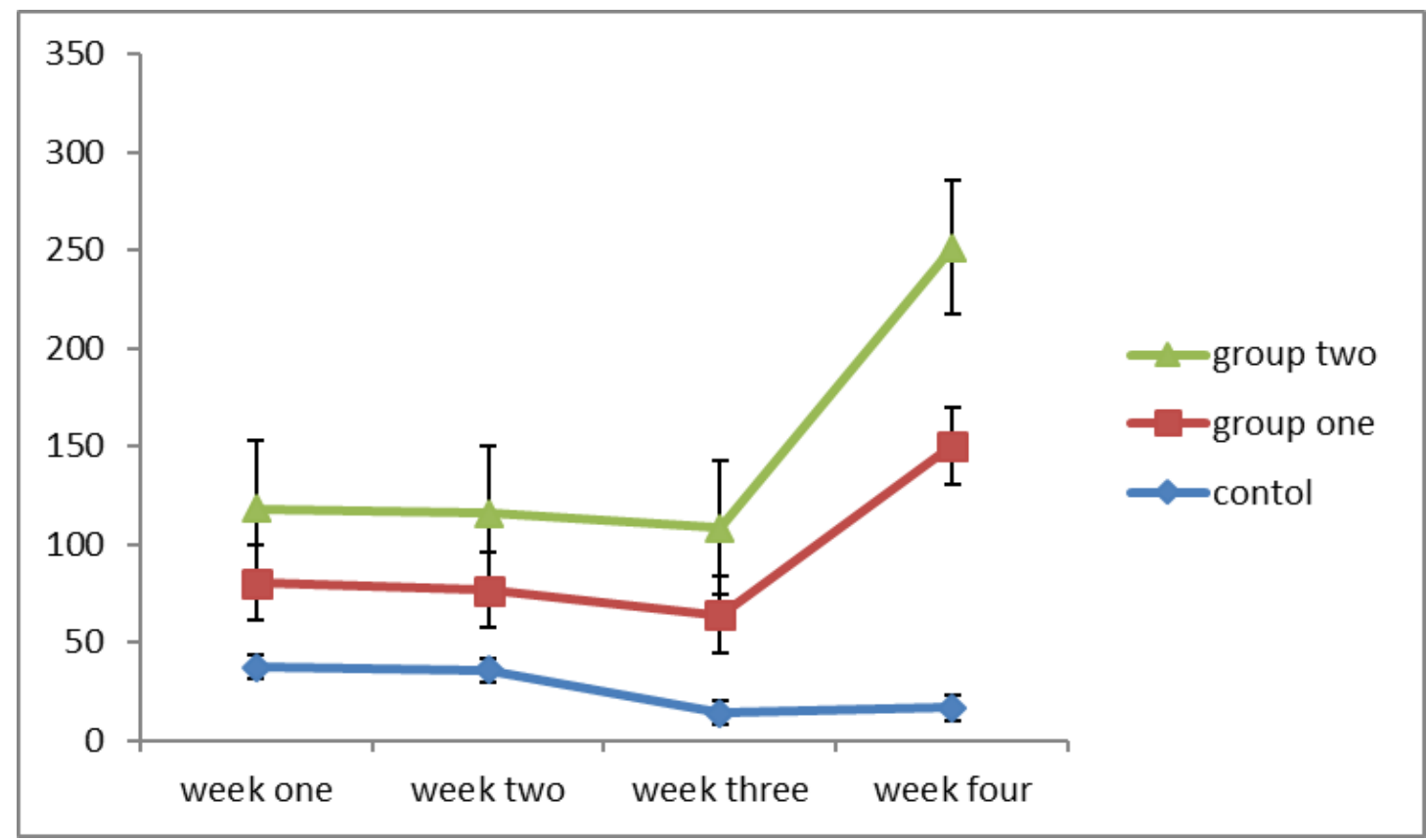

Figure 9. Shows the comparative illustration of the changes in the plasma LDL levels from week 1 to week 4 in the rabbits administered with both aqueous extract and methanolic extract of corn silk.

Group One: Aqueous Extract

Group Two: Methanolic Extract 


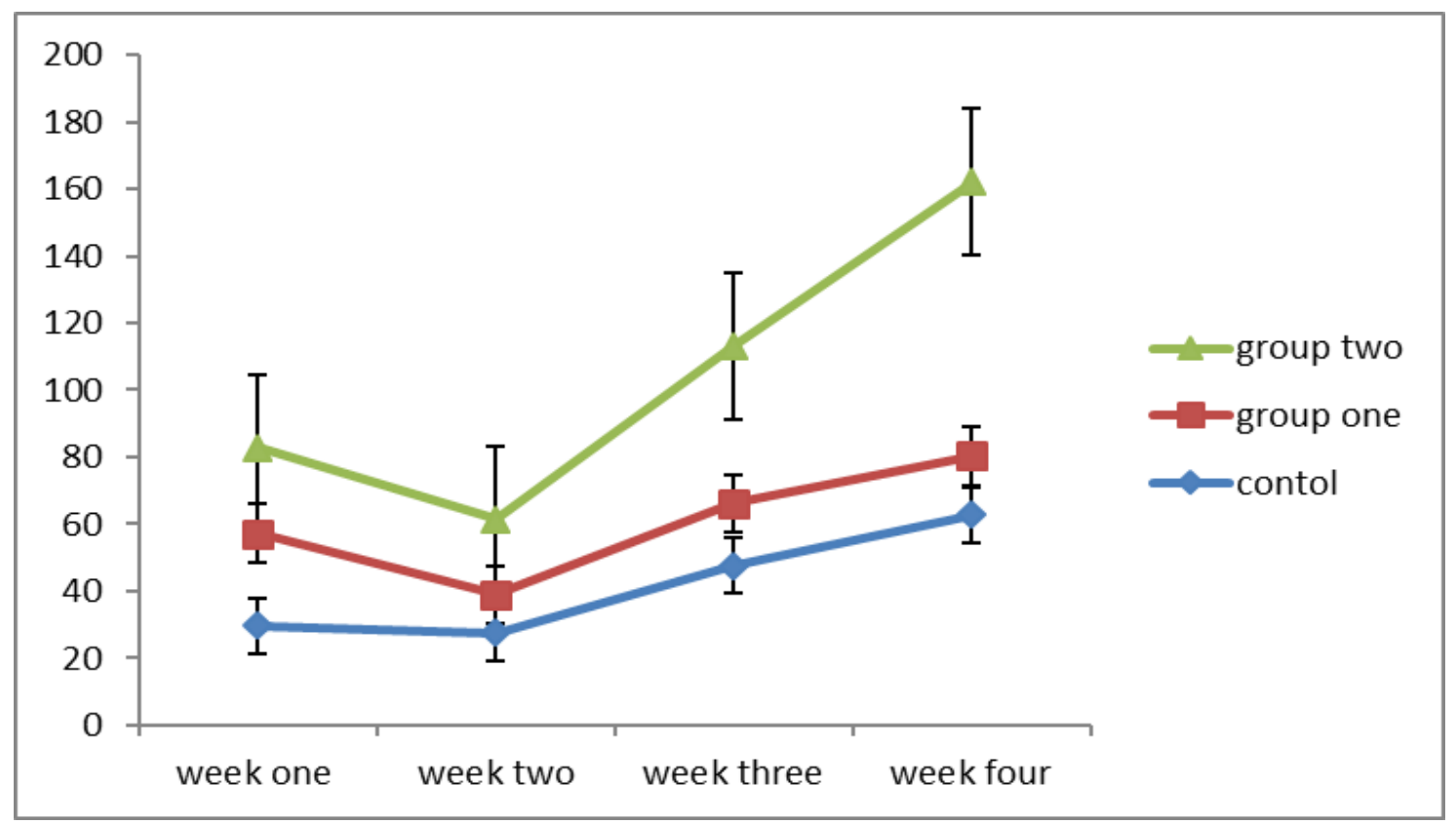

Figure 10. Shows the comparative illustration of the changes in the plasma CKMB activity from week 2 to week 4 in the rabbits administered with both aqueous extract and methanolic extract of corn silk.

Group One: Aqueous Extract

Group Two: Methanolic Extract

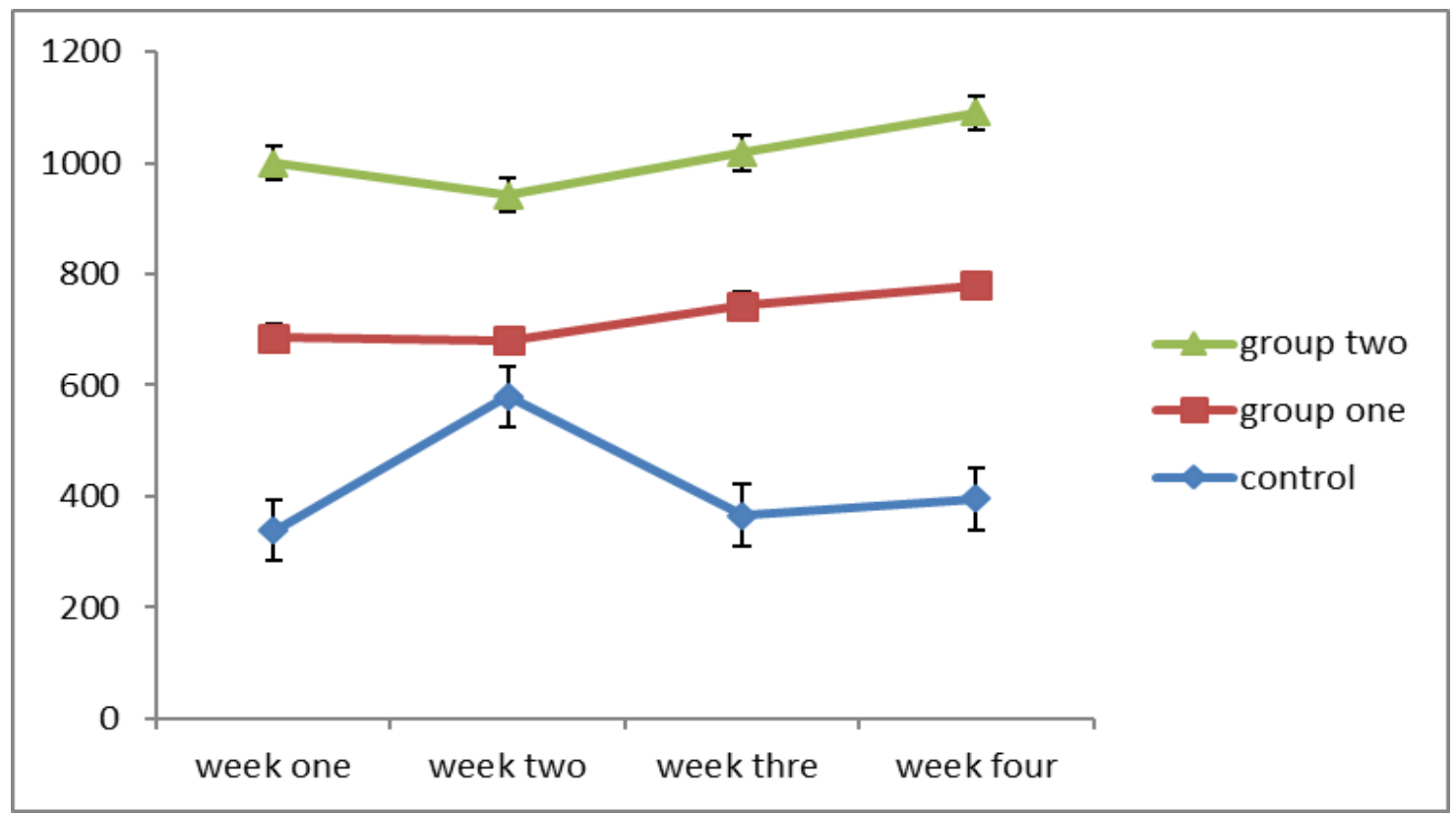

Figure 11. Shows the comparative illustration of the changes in the plasma LDH activity from week 1 to week 4 in the rabbits administered with both aqueous extract and methanolic extract of corn silk.

Group One: Aqueous Extract

Group Two: Methanolic Extract 


\section{Discussion}

There was a significantly higher mean value of plasma Total Cholesterol Triglyceride in the control rabbits than the results obtained in the test rabbits after one week of the administration of methanolic and aqueous extract of corn silk. The above findings agrees with the reports of Zhang et al. [11] on the process of microwaveassisted extraction (MAE) of total flavonoids from corn silk and the hypolipidemia in animal models that corn silk total flavonoids (CSTF) significantly lowered the serum TC, TG and LDL-C levels. The serum lipid level was decreased by CSTF in hyperlipidemic animal models in a dose dependent manner.

There was a significantly lower mean value of plasma Total Cholesterol and Triglyceride in the control rabbits than the results obtained in the test rabbits after two and three weeks of the administration of methanolic and aqueous extract of corn silk. There was a significantly lower mean value of plasma LDL- Cholesterol in the control rabbits than the results obtained in the test rabbits after 2 and 3 weeks of the administration of methanolic and aqueous extract of corn silk.

The above findings does not agree with the reports of Zhang et al. [11] on the process of microwave-assisted extraction (MAE) of total flavonoids from corn silk and the hypolipidemia in animal models that corn silk total flavonoids (CSTF) significantly lowered the serum TC, TG and LDL-C levels. The serum lipid level was decreased by CSTF in hyperlipidemic animal models in a dose dependent manner.This is probably due to the high lipid content of $2.5 \%$ fats in corn silk [7]. This is probably due to the high lipid content of $2.5 \%$ fats in corn silk [7].

There was a significantly lower mean plasma CK-MB value in the test rabbits than the control rabbits after 3 weeks of administration of aqueous extract of corn silk. This could be attributed to the antihypertensive effect of corn silk extract. Diaoyu et al. [12] reported antihypertensive effect of corn silk extract and a significant decrease in heart rate in rabbits.

\section{Conclusion}

There was a significant decrease in Cholesterol and Triglyceride in the rabbits after one week of methanolic extract but prolong administration of the extract significantly increased the Cholesterol, Triglycerides and LDL-Cholesterol. The corn silk extract also has a lowering effect on CK-MB in rabbits administered with corn silk extract.

\section{Recommendation}

Estimation of plasma CK-MB, Cholesterol, Triglyceride and LDL-Cholesterol in patient undergoing treatment with corn silk extract will be a useful indicies for effective management.

\section{Reference}

1. Ramessar K, Rademacher T, Sack M, Stadlmann J, Platis D, Stiegler G, Labrou N, Altmann F, Ma J, Stöger E, Capell T, Christou P (2008) Costeffective production of a vaginal protein microbicide to prevent HIV transmission. Proc Natl Acad Sci USA 105:3727-3732. doi: 10.1073/pnas.0708841104 [PMC free article] [PubMed]

2. Naqvi S. Habib, M. Umar Dahot, Asghar Ali. M. Yakoub Khan and M. Rafiq(2011) Production and characterization of extracellular lipasesecreted by Mucor geophillus . African Journal of Biotechnology Vol. 10(84), pp. 1959819606

3. Maksimovic, Z. and Kovacevic, N. (2003). Preliminary assay on the antioxidative activity of Maydis stigma extracts. Fitoterapia (74): 144147. doi: 10.1016/S0367-326X(02)00311-8

4. Hu, Q. L.; Zhang, L. J.; Li, Y. N.; Ding, Y. J. and Li, F. L. (2010). Purification and antifatigue activity of flavonoids from corn silk. International Journal of Physical Sciences; 5(4): 321 - 326. 
5. Ebrahimzadeh, M.A., Pourmorad, F. and Hafezi, S. (2008) Antioxidant activities of Iranian corn silk. Turkish Journal of Biology, (32): 43-49.

6. Rosli, W. I.; Nurhanan, A. R.; Solihah, M. A. and Mohsin, S. S. J. (2011). Corn silk improves nutrient content and physical characteristics of beef patties. Sains Malaysian journal of food science 40 (2): 155 - 161.

7. Abdel-Wahab, S. M., El-Tanbouly, N. D., Kassem, H. A. and Mohamed, E. A. (2002). Phytochemical and biochemical study of corn silk (styles and stigmas of Zea mays L.). journal of Pharmacy (40): 93-102.

8. Friedewald WT, Levy RL, Fredrickson DS (1972) Estimation of the concentration of lowdensity lipoprotein cholesterol in plasma, without use of the preparative ultracentrifuge. Clin Chem. Jun;18(6):499-502.
9. Jensen,William B.(2007). The origin of the soxhlet extractor. Journal of chemical education.(ACS), 84(12) :1913-1914. doi: 10.1021/ed084p1913

10. Allain, C. C.; Poon, L. S.; Chan, C. S. G., et al(1974) Enzymatic determination of total serum cholesterol. Clin. Chem. 20:470-475; 1974.» PubMed

11. Zhang M.A Perera,.D.N., Qin, W., YandeauNelson, M., Fan, L., Dixon, P. and Nikolau, B.J. (2011). Biological origins of normal-chain hydrocarbons: a pathway model based on cuticular wax analyses of maize silks. Plant Journal . (64): 618-632

12. Diaoyu ,Namba T, Xu H, Kadota S, Hattori M, and Takahashi $T$ (2003) phytochemical and scientific study and functionsof corn silk. Journal of chinese herbal medicine154(14) :1125-1189. 